\title{
Solving inverse Sturm-Liouville problem featuring a constant delay by Chebyshev interpolation method
}

\author{
Abdol Dabbaghian ${ }^{1}$, Shahrbanoo Akbarpoor ${ }^{1}$, Hikmet Koyunbakan ${ }^{2}$, and Bahram Agheli ${ }^{3}$ \\ ${ }^{1}$ Islamic Azad University \\ ${ }^{2}$ Firat University \\ ${ }^{3}$ Qaemshahr Islamic Azad University
}

September 21, 2020

\begin{abstract}
The inverse nodal problem for Sturm-Liouville operator with a constant delay has been investigated in the present paper. To do so, we have computed the nodal points and nodal lengths. Therefore, we have tried Chebyshev interpolation method to obtain the numerical solution of inverse nodal problem. Following that, a number of numerical examples have been given. The numerical calculations in the present paper have been conducted via pc applying some programs encoded in Matlab software.
\end{abstract}

\section{Hosted file}

Sample.pdf available at https://authorea.com/users/360777/articles/482315-solving-inversesturm-liouville-problem-featuring-a-constant-delay-by-chebyshev-interpolation-method

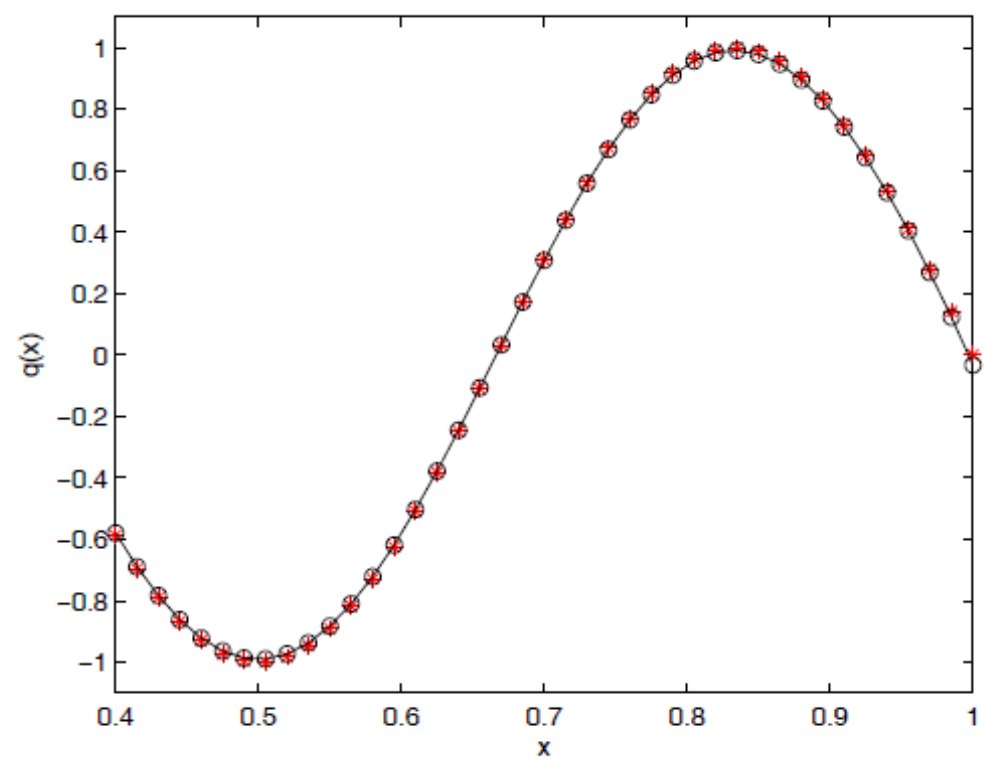




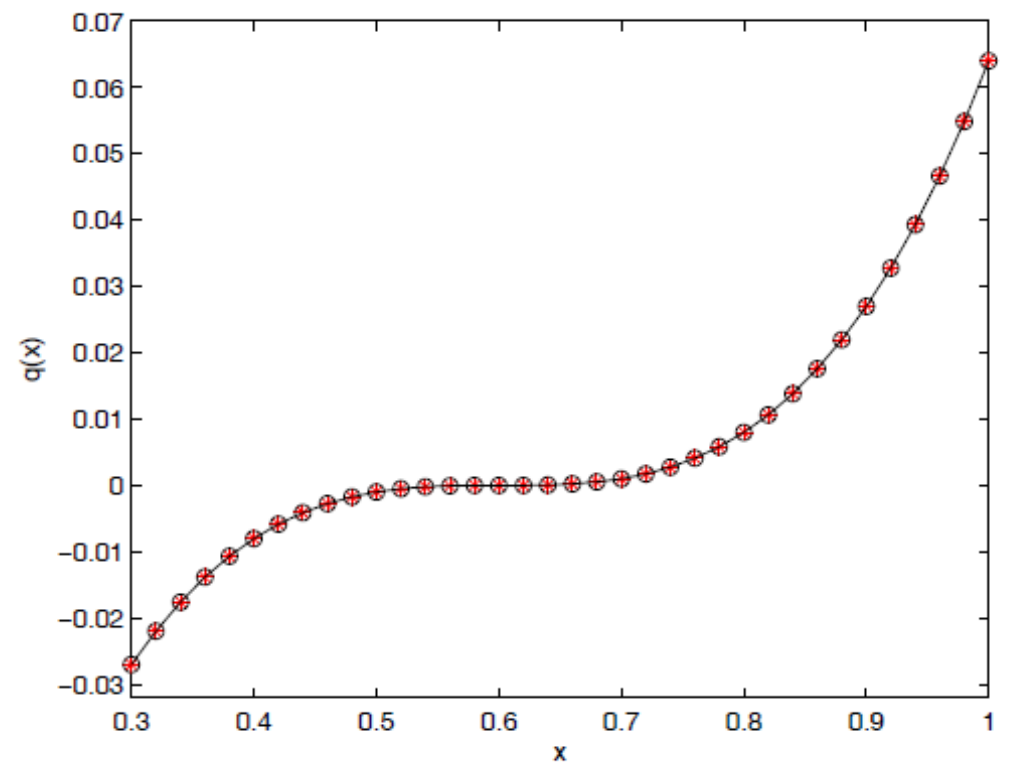

